\title{
Physical attractiveness, self-awareness, and mirror-gazing behavior
}

\author{
ADAM L. LIPSON \\ State University of New York, Albany, New York 12222 \\ DAVID P. J. PRZYBYLA \\ Colgate University, Hamilton, New York 13346 \\ and \\ DONN BYRNE \\ State University of New York, Albany, New York 12222
}

\begin{abstract}
In a field study, 86 students ( 37 males and 49 females) were observed as they walked past a section of reflecting glass that served as a mirror. The amount of time spent by each subject in gazing at his or her own image was recorded. The physical attractiveness of each participant was rated by experimental observers, and subjects filled out a questionnaire that assessed the degree to which they ordinarily engage in self-focused behavior. For both males and females, time spent in mirror gazing was positively correlated with physical attractiveness. Mirror gazing and self-focusing were unrelated, although self-focusing was positively correlated with attractiveness.
\end{abstract}

McDonald and Eilenfield (1980) reported that the time spent looking at one's own image while passing a mirror is a positive function of physical attractiveness. Thus, attractive individuals exhibit an approach response to mirror gazing compared to less attractive individuals. In the present investigation, an attempt was made to extend these findings to a dispositional variable consisting of individual differences in attending to self vs. the external environment.

Gibbons and Wicklund (1976) have reported that negative discrepancy from one's self-perception is aversive. Such discrepancy involves a negative evaluation of self relative to one's own standard (e.g., seeing one's image in a mirror as being less attractive than anticipated). In contrast, positive discrepancy involves a positive evaluation of self relative to one's standard (e.g., seeing one's image in a mirror as being more attractive than anticipated). Gibbons and Wicklund induced a state of either positive or negative discrepancy, after which they gave subjects the opportunity to listen to their own voices or to an anonymous voice reading a passage. It was found that subjects with positive discrepancy spent more time listening to their own voices, whereas subjects with negative discrepancy spent more time listening to the anonymous voice. The investigators proposed that positive discrepancy leads to an approach response and negative discrepancy to an avoidance response, provided that no remedy is available to relieve the imbalanced state. Steenbarger and Aderman (1979) suggest that negative discrepancy from perceived self will have an aversive effect only if the individual feels that the discrepancy is of a stable nature (e.g., physical attractiveness).

Duval and Wicklund (1972) theorize that there are two mutually exclusive states of awareness that are distinguished by the individual's attention toward either external variables or himself or herself. Ordinarily, the former state is dominant. Attention toward self is exercised sporadically, and this self-awareness mode is triggered by any stimulus that reminds the individual of his or her object-like properties (e.g., the presence of a mirror). This process of self-awareness is one of evaluation and introspection, and it focuses on the relevant aspect of self for a specific situation. There are also individual differences in the tendency to engage in self-focused behavior (Fenigstein, Scheier, \& Buss, 1975). If a mirror induces self-focusing, it would seem to follow that those who self-focus to the greatest extent tend to gaze at their own reflections more than do those who fail to self-focus.

It was hypothesized that those individuals who are high in self-focusing tendencies, as well as those who are high in physical attractiveness, spend more time in mirror gazing than those who are low in self-focusing or attractiveness.

\section{METHOD}

\section{Subjects}

Individuals selected for inclusion in the investigation were males and females on a university campus who were approaching a recreational/sunning area that had a continuous series of plate glass windows along its perimeter. The section of glass was 
$14 \mathrm{ft}$ high and $60 \mathrm{ft}$ long. Duration of self-observation was recorded (in 10ths of seconds), and attractiveness ratings were made for Caucasian individuals who appeared to be of college age as they walked past the reflecting glass.

\section{Procedure}

In order for an individual to gaze at his or her image, it was necessary for the person's head to turn through a 90-deg arc. If a subject looked at the glass and turned away but then looked a second time, the duration of the two observations were summed.

The physical attractiveness of the subjects was independently assessed on a scale from 1 (extremely unattractive) to 5 (extremely attractive) by two to four raters, in each instance including at least one male and one female. Raters ostensibly were studying at a distance of approximately $30 \mathrm{ft}$ from the end of the mirrored area.

As each subject reached the end of the glass, he or she was greeted by an experimenter who asked that individual to complete the Private Self-Consciousness Scale (Fenigstein et al., 1975), the measure of self-focusing tendencies.

\section{RESULTS}

For the assessment of physical attractiveness, interjudge reliability was acceptably high $(\mathrm{r}=.74)$. Because private self-consciousness and physical attractiveness were positively associated $(r=.24, p<.05)$, the relationship of each to mirror-gazing behavior was determined while the effects of the other were held constant.

Duration of mirror gazing was found to be significantly related to physical attractiveness (with private self-consciousness partialed out) for both males $\left(\mathrm{r}_{12.3}=\right.$ $.54, \mathrm{p}<.0001)$ and females $\left(\mathrm{r}_{12.3}=.32, \mathrm{p}<.05\right)$. Duration and private self-consciousness (controlling for physical attractiveness) were not significantly related for either sex, although the partial correlation for males approached significance $\left(\mathrm{r}_{13.2}=.25, \mathrm{p}<.06\right)$. In addition, duration scores were subjected to a 2 by 2 by 2 analysis of variance with the factors of sex (male vs. female), attractiveness (above and below the median), and private self-consciousness (above and below the median). None of the interactions was significant, and physical attractiveness was the only main effect demonstrated $[\mathrm{F}(1,78)=14.65, \mathrm{p}<.0001]$.

\section{DISCUSSION}

For both males and females, physical attractiveness was found to be positively associated with the duration of selfobservation while passing a mirror. Thus, the McDonald and Eilenfield (1980) results were replicated.

The attempt to establish a relationship between self-focusing tendencies and mirror gazing was unsuccessful. Although it was found that physical attractiveness is positively associated with the tendency to engage in self-focusing behavior, only the former variable contributes independently to looking at one's reflected image.

\section{REFERENCES}

Duval, S., \& Wicklund, R. A. A theory of objective selfawareness. New York: Academic Press, 1972.

Fenigstein, A., Scheier, M. F., \& Buss, A. H. Public and private self-consciousness: Assessment and theory. Journal of Consulting and Clinical Psychology, 1975, 43, 522-527.

Gibbons, F. X., \& Wicklund, R. A. Selective exposure to the self. Journal of Research in Personality, 1976, 10, 98-106.

McDonald, P. J., \& Eilenfield, V. C. Physical attractiveness and the approach/avoidance of self-awareness. Personality and Social Psychology Bulletin, 1980, 6, 391-395.

Steenbarger, B. N., \& Aderman, D. Objective self-awareness as a nonaversive state: Effect of anticipation discrepancy reduction. Journal of Personality, 1979, 47, 330-339.

(Received for publication January 31, 1983.) 